\title{
Manatee (Trichechus manatus) vocalization usage in relation to environmental noise levels
}

\author{
Jennifer L. Miksis-Olds ${ }^{a)}$ \\ Applied Research Laboratory, The Pennsylvania State University, P.O. Box 30, State College, \\ Pennsylvania 16804 \\ Peter L. Tyack \\ Department of Biology, Woods Hole Oceanographic Institution, Woods Hole, Massachusetts 02543
}

(Received 5 August 2008; revised 8 December 2008; accepted 12 December 2008)

\begin{abstract}
Noise can interfere with acoustic communication by masking signals that contain biologically important information. Communication theory recognizes several ways a sender can modify its acoustic signal to compensate for noise, including increasing the source level of a signal, its repetition, its duration, shifting frequency outside that of the noise band, or shifting the timing of signal emission outside of noise periods. The extent to which animals would be expected to use these compensation mechanisms depends on the benefit of successful communication, risk of failure, and the cost of compensation. Here we study whether a coastal marine mammal, the manatee, can modify vocalizations as a function of behavioral context and ambient noise level. To investigate whether and how manatees modify their vocalizations, natural vocalization usage and structure were examined in terms of vocalization rate, duration, frequency, and source level. Vocalizations were classified into two call types, chirps and squeaks, which were analyzed independently. In conditions of elevated noise levels, call rates decreased during feeding and social behaviors, and the duration of each call type was differently influenced by the presence of calves. These results suggest that ambient noise levels do have a detectable effect on manatee communication and that manatees modify their vocalizations as a function of noise in specific behavioral contexts. (C) 2009 Acoustical Society of America. [DOI: 10.1121/1.3068455]
\end{abstract}

PACS number(s): 43.80.Nd [WWA]

Pages: 1806-1815

\section{INTRODUCTION}

Environmental noise has the potential to interfere with acoustic communication by masking signals containing biologically important information. Communication theory recognizes several ways a sender can modify its acoustic signal to compensate for noise. These include increasing the source level of a signal (Brumm, 2004; Scheifele et al., 2005), its repetition (Penna et al., 2005), its duration (Foote et al., 2004; Miller et al., 2000), shifting frequency outside of the noise band (Lesage et al., 1999; Brumm and Slabbekoorn, 2005; Parks et al., 2007), and altering the timing of signals to correspond with periods of less noise (Brumm and Slabbekoorn, 2005; Sun and Narins, 2005; Parks et al., 2007; SousaLima and Clark, 2008). All of these phenomena have been demonstrated in birds exposed to noise from natural sources (Lengagne et al., 1999; Slabbekoorn and Peet, 2003; Brumm, 2004; Brumm and Slater, 2006) and to marine mammals exposed to anthropogenic noise (Lesage et al., 1999; Miller et al., 2000; Parks, 2003; Foote et al., 2004; Scheifele et al., 2005; Parks et al., 2007).

The effective range of acoustic communication (or acoustic active space) in the marine environment depends on the acoustic propagation loss characteristics of the area, the frequency and amplitude of the vocalizations being emitted, the hearing sensitivity of the animal, and the ambient noise.

${ }^{a)}$ Electronic mail: jlm91@psu.edu
The importance of maintaining contact, and the required range of communication, depends on behavioral context. For example, it may be critical for a mother to maintain contact with her young, but this may be over a relatively short range if mother and young do not separate far. Members of a loose group of adults might separate over greater distances, but missed reunion cues may be less costly compared to interactions between mothers and calves.

The effective range of vocalizations may also be affected by environmental noise level. If the frequency of a vocalization overlaps with that of noise, this may mask significant signal information within the call, consequently interfering with communication. However, compensation mechanisms used to reduce the effect of noise likely involve a cost. Calls with a high probability of detection may be intercepted by predators, although this is not a significant cost to manatees because they have no natural nonhuman predators. Increased harassment of females by roving males may be another potential cost resulting from high call rates between mothers and calves (Hartman, 1979; Bengston, 1981; O'Shea and Hartley, 1995; Sousa-Lima et al., 2008). Louder and longer calls take more energy to produce, and if producing a call out of the normal frequency band is less efficient for the sound production apparatus, this may take more energy as well (Ryan, 1986). This balance of cost and benefit suggests that animals are likely to modulate signaling behavior to maintain effective communication out to the likely range of expected receivers, but that they may not 
always signal to achieve the maximum possible range. The extent to which animals engage costly mechanisms to compensate for noise may also depend on the cost of failing to communicate (e.g., when a mother and dependent young are separated). Thus signaling behavior including compensation for noise should depend on the behavioral context, the cost of failure to communicate, and the distribution of receivers.

Vocalizations are assumed to form the basis of most long range communication in marine mammals, as sound has the potential to travel rapidly over long distances in water, providing a reliable medium for manatees to communicate beyond visual range in murky coastal or riverine waters (Sousa-Lima et al., 2002). The impact of noise may become even more crucial for manatee acoustic communication during the summer months when vision is reduced due to high turbidity. Previous studies describing West Indian manatee (Trichechus manatus) vocalizations allude to the presence of two different vocalization types: tonal harmonic calls and broader-band, less tonal calls (Schevill and Watkins, 1965; Bengtson and Fitzgerald, 1985; Nowacek et al., 2003; SousaLima et al., 2008). However, this differentiation has not been quantified, and authors either analyzed only one call type or combined all call types in their rate and source level analyses. The present study quantitatively classified the vocalizations into two separate categories based on call structure. Analyses of usage were then performed separately for each call type. The identification of two acoustically distinct categories of manatee vocalizations may provide some insight into their function. The presence of individually stereotyped vocalizations in the repertoire of captive Amazonian and Antillean manatees provides evidence in support of the idea that manatee vocalizations function to establish and maintain contact between individuals (Sousa-Lima et al., 2002, 2008).

The goal of this paper is to study how manatees vary their vocal output to compensate for noise in different kinds of social groups and in different behavioral contexts. This species inhabits the shallow coastal waters near Sarasota, FL year round, although greatest numbers are observed in the nonwinter months when the water is most turbid. The grassbed habitats and shallow dredged basins that manatees utilize are environments where low frequency sound does not propagate as far as in the deep ocean (Miksis-Olds and Miller, 2006; Urick, 1983). The frequencies that propagate best are between 1 and $2 \mathrm{kHz}$ (Miksis-Olds and Miller, 2006), a band which coincides with the dominant frequencies of manatee vocalizations (Nowacek et al., 2003). Thousands of boats cause considerable variation in noise levels, which vary systematically on an hourly basis during the day and on a weekly basis including weekends and weekdays. MiksisOlds et al. (2007) demonstrated that this variation affects how manatees utilize specific habitats. Here we study whether manatees alter their vocalizations based on ambient noise levels, and whether they show context dependent compensation for noise in their extremely shallow coastal environment.

\section{METHODS}

\section{A. Acoustic recordings}

Vocalizations and ambient noise were recorded continuously throughout all group sightings and individual focal follows from a towed hydrophone system. The observation vessel maintained a 25-50 m distance to the individual or group of animals being recorded. The recording system contained an HTI-99-HF hydrophone with built-in preamplifier. This hydrophone had an operational frequency range of $2-125000 \mathrm{~Hz}$ and a sensitivity of $-178 \mathrm{~dB}$ re $1 \mathrm{mV} / \mathrm{Pa}$. The hydrophone was calibrated prior to and following each field season via comparison to a reference transducer. The analog signal was transferred to a Dell Inspiron 8110 laptop computer via a National Instruments PCMCIA DAQ Card-6062E with 12 bit resolution. The input range of the analog-todigital converter (ADC) was set to $\pm 1 \mathrm{~V}$ for all recordings. The 12 bit data were then converted and stored at 16 bit resolution using the CHICKADEE multichannel recorder version $1.9 \mathrm{~b}$ software program. The system noise was dominated by discretization noise (Oppenheim et al., 1999) and was well below the minimum detectable signal. Only vocalizations emitted at times when the trolling motor on the observation vessel was off were used in analyses. This was done in order to eliminate any potential response of the animals to the sound of the motor that was used to follow them during observation periods. Vocalization analysis was not designed to account for potential vocalization responses to transitions of the trolling motor being turned on and off during the focal follow.

Broadband recordings of ambient noise were made at the beginning and end of each sighting and/or follow when all motors were off and the boat was drifting. The sampling rate was $200 \mathrm{kHz}$. Noise levels were calculated in three $1 / 3$ octave bands with center frequencies of $500 \mathrm{~Hz}, 4 \mathrm{kHz}$, and $32 \mathrm{kHz}$. System noise of the recording system was below all ambient noise levels at all $1 / 3$ octave bands. Three $1 / 3$ octave band categories were selected to represent low, mid, and high frequency noises (LFN, MFN, and HFN, respectively) in manatee habitats. From the perspective of the manatee, the noise categories were designed to correspond to specific environmental signals and hearing capabilities. The LFN band $(500 \mathrm{~Hz})$ was selected to match the dominant frequencies of watercraft and other human activities that have the potential to cause bodily injury and mask vocalizations. MFN (4 kHz) directly overlapped with the dominant frequency of manatee vocalizations and had a high potential for masking. Finally the HFN band $(32 \mathrm{kHz})$ was reported to be outside the most sensitive areas of hearing for manatees (Ketten et al., 1992; Gerstein et al., 1999). A detailed description of the noise components and spectral content of manatee habitats in Sarasota Bay can be found in Miksis-Olds et al. (2007).

\section{B. Behavioral states}

Manatees were observed to engage in five behavioral states throughout the study: social, mill, travel, rest, and feed. Social behaviors were defined as the direct interaction between one or more manatees and include mating, herding, and playing. Milling behavior was characterized by undi- 
rected movement, and traveling was characterized by directed movement. Resting behavior was identified by repeated surfacing in the same location in the absence of feeding. Feeding was identified by the observation of food ingestion evident by grass in mouth or cropped grasses floating in the vicinity.

Analysis of vocalizations included only those produced when an entire group of manatees under observation was engaged in the same behavior or only a single animal was being observed. This is consistent with the methodology of Bengtson and Fitzgerald (1985). An additional criterion for inclusion in the behavior analysis was that the recording lasted a minimum of $20 \mathrm{~min}$. Ten of the 99 recordings were shorter than $20 \mathrm{~min}$ and were eliminated from analysis. The 20 min time period was selected because it was the minimum amount of time needed to approach a group and accurately determine behavioral state, number of animals, and calf presence. Estimating the number of manatees and behavior classification are both potential sources of error in the analyses. The number and behavior of manatees may have been misidentified in turbid waters although the number of animals obtained from the observation vessel compared well with simultaneous aerial survey counts from a low flying aircraft. No discrepancies occurred for groups of five animals or fewer. In 13 comparisons, the maximum difference between the aerial survey and on-water counts was two animals for groups with a minimum of six individuals and ranging from 6 to 20 total animals. The on-water counts underestimated the number of manatees present in all comparisons. Another possible source of error was that animals nearby or approaching the observed group could have introduced vocalizations while in a different behavioral state.

\section{Vocalization rate}

The number of vocalizations used from each recording was determined according to the following protocol. The protocol was implemented to account for the context dependent usage of vocalizations during different behavioral states. Recordings made when animals were continuously observed engaging in the same behavior were divided into $20 \mathrm{~min}$ time periods; a $2 \mathrm{~h}$ recording made while animals were resting would contain six nonoverlapping time periods. The $20 \mathrm{~min}$ block selected to initiate the vocalization rate analysis for each behavioral state was randomly identified to prevent bias of rate changes associated with behavioral transitions (such as always starting at the beginning of an observed behavior). Vocalizations continued to be identified in $20 \mathrm{~min}$ time periods within the same behavioral state until a total of 200 vocalizations were reached, the behavioral state changed, or the recording ended. Because of the great number of vocalizations produced during social interactions, a separate criterion was applied to this state. For social behaviors only, if more than 200 vocalizations were obtained within the first randomly selected 20 min time period, no further vocalizations were identified from that behavioral state on a single recording. Vocalization rates were calculated in $20 \mathrm{~min}$ blocks and were presented as the number of vocalizations per manatee per 5 min period to maintain consistency with pre-
TABLE I. Kolmogorov-Smirnov normality test statistics.

\begin{tabular}{|c|c|c|c|}
\hline Category & Covariate parameter & $D$ value & $p$ value \\
\hline & Average rate & 0.092 & $>0.15$ \\
\hline & LFN & 0.074 & $>0.15$ \\
\hline & MFN & 0.104 & 0.06 \\
\hline & HFN & 0.091 & $>0.15$ \\
\hline & Group size & 0.120 & $<0.01$ \\
\hline \multirow[t]{10}{*}{ Chirp } & Average source level & 0.110 & 0.08 \\
\hline & Average duration & 0.089 & $>0.15$ \\
\hline & Average freq. range & 0.090 & $>0.15$ \\
\hline & Average min. freq. & 0.095 & $>0.15$ \\
\hline & Average max. freq. & 0.110 & 0.06 \\
\hline & Average peak freq. & 0.080 & $>0.15$ \\
\hline & LFN & 0.080 & $>0.15$ \\
\hline & MFN & 0.100 & 0.1 \\
\hline & HFN & 0.110 & 0.06 \\
\hline & Group size & 0.130 & 0.01 \\
\hline \multirow[t]{10}{*}{ Squeak } & Average source level & 0.110 & 0.13 \\
\hline & Average duration & 0.120 & 0.1 \\
\hline & Average freq. range & 0.093 & $>0.15$ \\
\hline & Average min. freq. & 0.094 & $>0.15$ \\
\hline & Average max. freq. & 0.120 & 0.06 \\
\hline & Average peak freq. & 0.090 & $>0.15$ \\
\hline & LFN & 0.110 & $>0.15$ \\
\hline & MFN & 0.120 & 0.1 \\
\hline & HFN & 0.070 & $>0.15$ \\
\hline & Group size & 0.150 & $<0.01$ \\
\hline
\end{tabular}

vious studies (Bengtson and Fitzgerald, 1985; Phillips et al., 2004). Mean vocalization rate was calculated from multiple 20 min time periods within the same behavioral state from the same recording and averaged to produce a single rate value per manatee for each behavioral state within the recording; hence the recording was the unit of analysis.

\section{Vocalization structure}

Vocalizations included in the analysis of vocalization structure were subjected to the same selection criteria as those for the vocalization rate analysis. Subsets of these vocalizations were selected for structure analysis based on the following additional criteria: (1) a clear start and end to the vocalization was identified, (2) there were no overlapping signals, and (3) the received level (rms) was a minimum of 3 $\mathrm{dB}$ above the noise level over the same bandwidth. Parameters measured were number of inflection points, duration, minimum frequency, maximum frequency, frequency range, and frequency of peak energy. All parameters were measured by hand from a 512 point Fast Fourier Transform (FFT) spectrogram. Absolute level of the signal was not used as part of the structure analysis.

\section{E. Source level}

Vocalizations included in the source level analysis were subjected to the same selection criteria as those for the vocalization rate analysis. A subset of these vocalizations was selected for source level analysis based on the following ad- 
TABLE II. Effects tested in initial mixed model ANCOVA.

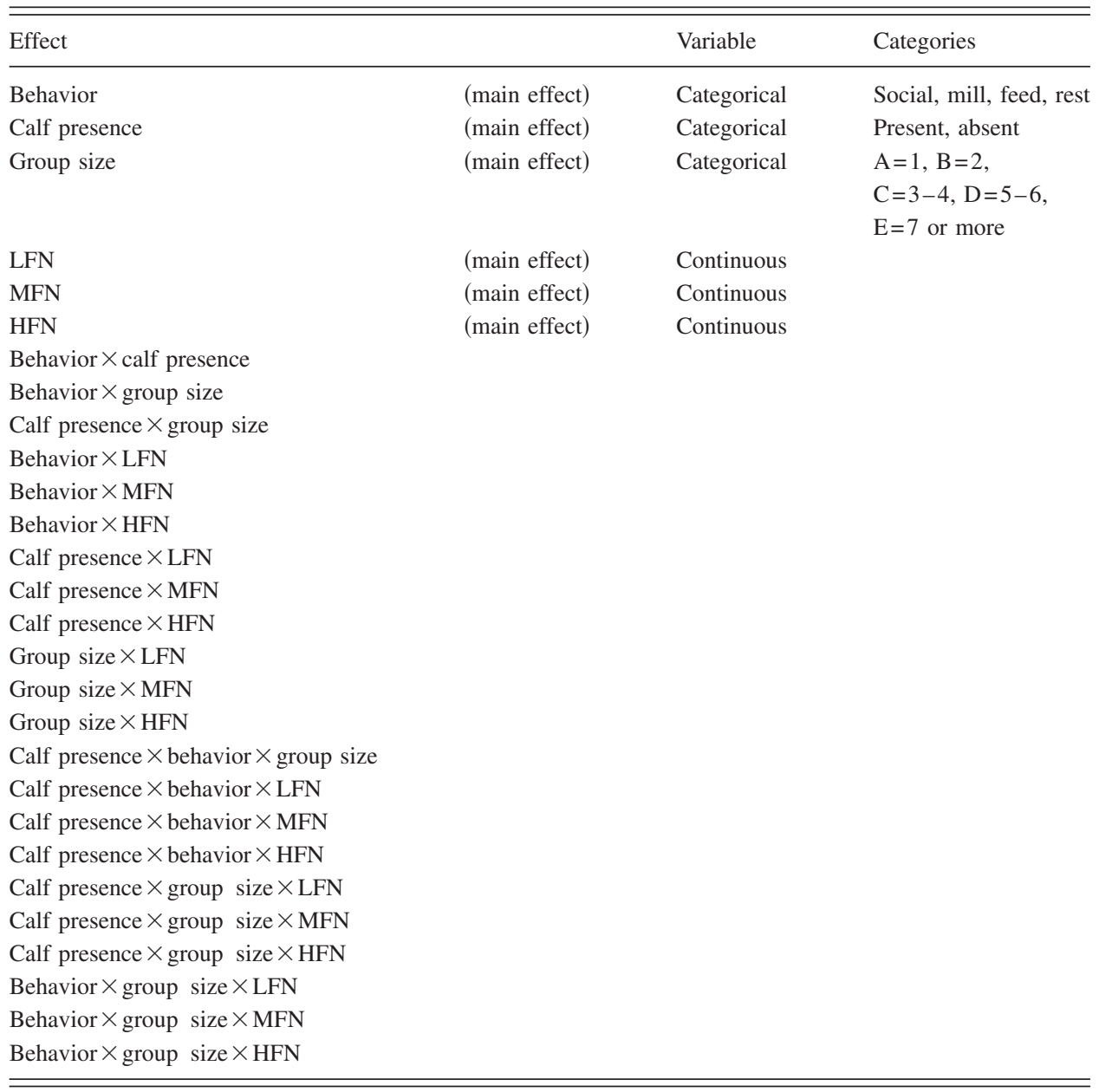

ditional criteria: (1) distance from a single animal or compact group of animals to the hydrophone was specified, (2) no other animals were observed within $500 \mathrm{~m}$, (3) a clear start and end to the vocalization was identified, and (4) there were no overlapping signals. Laser range finding binoculars were used to obtain the distance to the most likely vocalizing animal during surfacings. A compact group was defined as a group of animals (mother-calf pair, social group, etc.) within a $5 \mathrm{~m}$ radius which translated into a $5 \mathrm{~m}$ error in source level calculations. A $500 \mathrm{~m}$ distance was selected for criterion 2, as sound energy from vocalizing animals beyond $500 \mathrm{~m}$ would not be audible above the background noise (MiksisOlds and Miller, 2006; Miksis-Olds et al., 2007).

A fifth order Butterworth band pass filter was constructed and applied to each vocalization over the band of minimum and maximum signal frequencies selected by hand. A rms received level was then calculated over the duration of the vocalization. Final source level calculations were obtained by adding a transmission loss component which was specific to each animal distance and geographical site. Average transmission loss values generated from the MontereyMiami parabolic equation model (Smith, 2001) within each manatee habitat were obtained from Miksis-Olds and Miller (2006).

\section{F. Statistical analysis}

Kolmogorov-Smirnov normality tests were performed for all vocal response parameters (rate, source level, frequency range, minimum frequency, maximum frequency, and peak frequency of the dominant harmonic) and continuous covariates (group size, LFN, MFN, and HFN) (Table I). Group size was the only parameter shown not to be normally distributed. As a result, group size was converted to a categorical variable with five categories: (1) single animal, (2) pair of animals, (3) three to four animals, (4) five to six animals, and (5) seven or more animals.

A mixed model analysis of covariance (ANCOVA) was run to determine if noise level had an effect on vocal parameters. The unit of analysis was the recording. Manatees are not reported to be territorial, so recordings of vocalizations made at the same site on different days were highly unlikely to be from the same individuals. This was confirmed by photographs taken of each animal and compared to known animals in the Manatee Individual Photoidentification System (MIPS) maintained by the State of Florida. One recording per day was made at a site, and subsequent recordings on the same day were geographically separated by a minimum of 1 $\mathrm{km}$. Photoidentification was used to ensure that the same manatee was not recorded more than once on the same day. The probability of repeated recording of the same individual 
TABLE III. Noise levels for each behavior category in decibels re $1 \mu \mathrm{Pa}$. Min is the minimum level recorded during the designated behavior. Max is the maximum level recorded during the designated behavior. Average is the noise level over the range of the Q2 and Q3 quartiles.

\begin{tabular}{|c|c|c|c|c|c|c|c|c|c|c|c|c|}
\hline & \multicolumn{3}{|c|}{ Feed } & \multicolumn{3}{|c|}{ Mill } & \multicolumn{3}{|c|}{ Rest } & \multicolumn{3}{|c|}{ Social } \\
\hline & Min & Average & Max & Min & Average & Max & Min & Average & Max & Min & Average & Max \\
\hline LFN & 47 & $56-68$ & 80 & 38 & $51-59$ & 67 & 38 & $47-53$ & 67 & 47 & $51-65$ & 70 \\
\hline $\mathrm{MFN}$ & 45 & $52-66$ & 79 & 43 & $48-56$ & 65 & 40 & $48-52$ & 64 & 46 & $49-58$ & 68 \\
\hline HFM & 46 & $54-66$ & 80 & 45 & $53-64$ & 65 & 45 & $54-58$ & 66 & 44 & $53-59$ & 68 \\
\hline
\end{tabular}

was thus assumed to be low. Over the course of the 2 year study, only six animals were observed to be recorded more than once. One manatee was the focal animal in two follows, and five manatees were observed in different sightings on different days over the course of 1 year.

A separate model was run for each call parameter in the two call categories and included three categorical factors (behavior, calf presence, and group size) and three covariates (LFN, MFN, and HFN) (Table II) (Littell et al., 2006). The initial mixed model included 6 main effects, 12 two-factor interactions, and 10 three-factor interactions (Table II). Interactions between noise levels at different frequencies were not the focus of this study, so only one noise variable was included in each model interaction. The data set did not support four-factor interactions due to the low sample size in each statistical cell. The initial mixed model was then refined by a three-step elimination of nonsignificant factors ( $p$ $>0.60$ for three-factor interactions and $p>0.80$ for twofactor interactions). Interactions exceeding the designated significance thresholds were removed prior to the next mixed model run. Eliminations occurred three times, and the models were run four times to identify the final significant interactions.

Pairwise comparisons across states (feeding vs milling or calf absent vs calf present) within a category of significant interactions were made using least squares means with a Tukey-Kramer adjustment (Littell et al., 2006). In the least squares means comparisons, noise levels within each frequency category were tested at low noise levels (lower quartile), average noise levels (middle quartiles), and high noise levels (upper quartile) (Table III). Significant relationships within a categorical state and involving a continuous covariate interaction were identified with linear regression.

\section{RESULTS}

Over the course of the study, $103 \mathrm{~h}$ of vocalization recordings were obtained during 128 sightings, and 50 focal follows. Of the total recordings, $62.5 \mathrm{~h}$ met all the analysis criteria and were reviewed in detail. These were the hours when the manatees were observed either as a single animal or all animals within the observation group were engaged in the same behavior. The number of usable hours in each behavioral category, as well as the number of vocalizations identified, is outlined in Table IV.

A preliminary analysis was conducted to determine whether manatee vocalizations can be classified into two distinct vocalization types. The main classification parameter was the number of inflection points. Calls containing one or more inflection points were designated chirps (Fig. 1). Calls with no inflection points were defined as squeaks (Fig. 1). A classification and regression tree was not needed, as the vocalization categories were split cleanly from the root based on one parameter, which accounted for $100 \%$ of the variability. Chirps tended to have a clear tonal sound to them, whereas squeaks sounded raspy. Additionally, five traditional acoustic parameters were measured for each vocalization: duration, frequency range, minimum frequency, maximum frequency, and frequency of peak energy. A series of Bonferroni corrected $t$-tests showed that chirps and squeaks differed acoustically based on the five parameters measured (Table V). Chirps were longer in duration, had a broader frequency range, and were higher in frequency compared to the more raspy sounding squeaks. Based on these findings, chirps and squeaks were analyzed separately for patterns associated with behavior, calf presence, group size, and ambient noise. The classification in this study supports the verbal descriptions of different calls made previously by Schevill and Watkins (1965), Bengtson and Fitzgerald (1985), and Nowacek et al. (2003) where vocalizations were described as either as tonal harmonic calls or broader-band, less tonal, nonharmonically related calls that sounded squeaky or raspy. SousaLima et al. (2008) also identified the two vocalization types and presented the idea of a graded repertoire between the two call types. However, the study of Sousa-Lima et al. (2008)

TABLE IV. Behavior category breakdown of hours and identified vocalizations.

\begin{tabular}{lllccc}
\hline \hline Behavior & $\begin{array}{l}\text { Behavior } \\
(\mathrm{h})\end{array}$ & $\begin{array}{l}\text { Usable } \\
(\mathrm{h})\end{array}$ & Total vocalizations & Trolling motor off & Trolling motor on \\
\hline Social & 20 & 14.5 & 3083 & 2668 & 415 \\
Mill & 10.5 & 10 & 677 & 580 & 97 \\
Rest & 23 & 18 & 935 & 887 & 48 \\
Feed & 23.5 & 20 & 1326 & 1083 & 243 \\
Total & 77 & 62.5 & 6021 & 5218 & 803 \\
$\%$ of total & & & & $(86.7)$ & $(13.3)$ \\
\hline \hline
\end{tabular}


a)

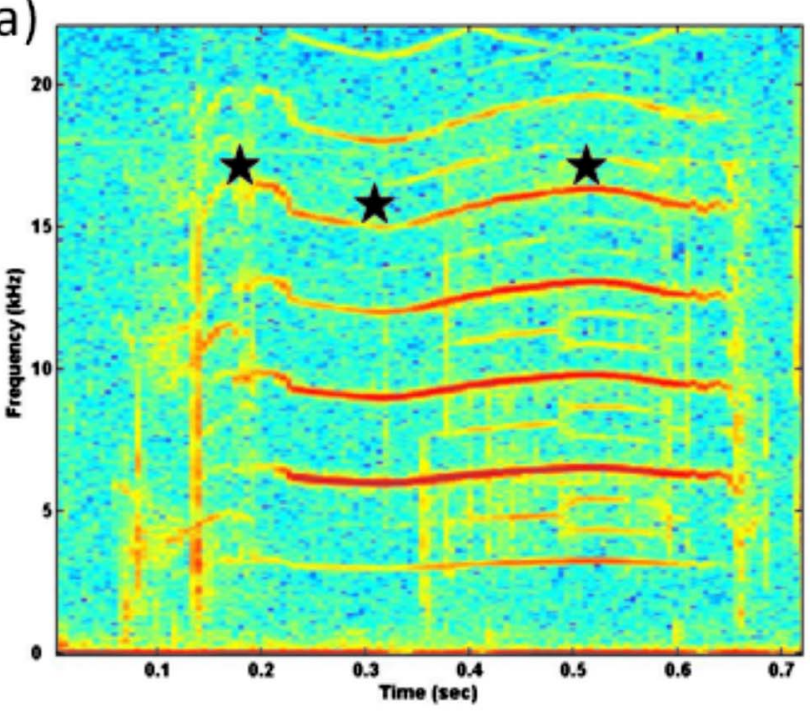

b)

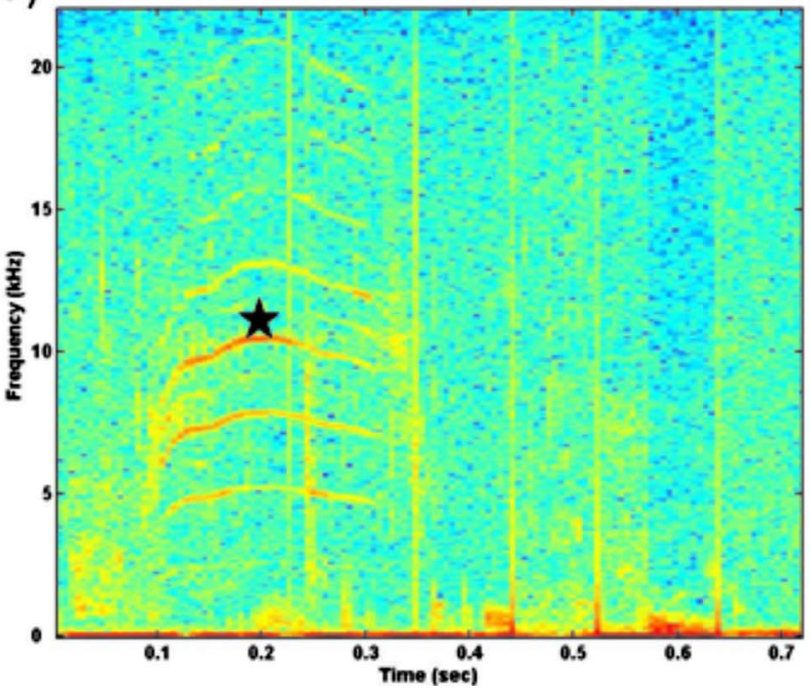

c)

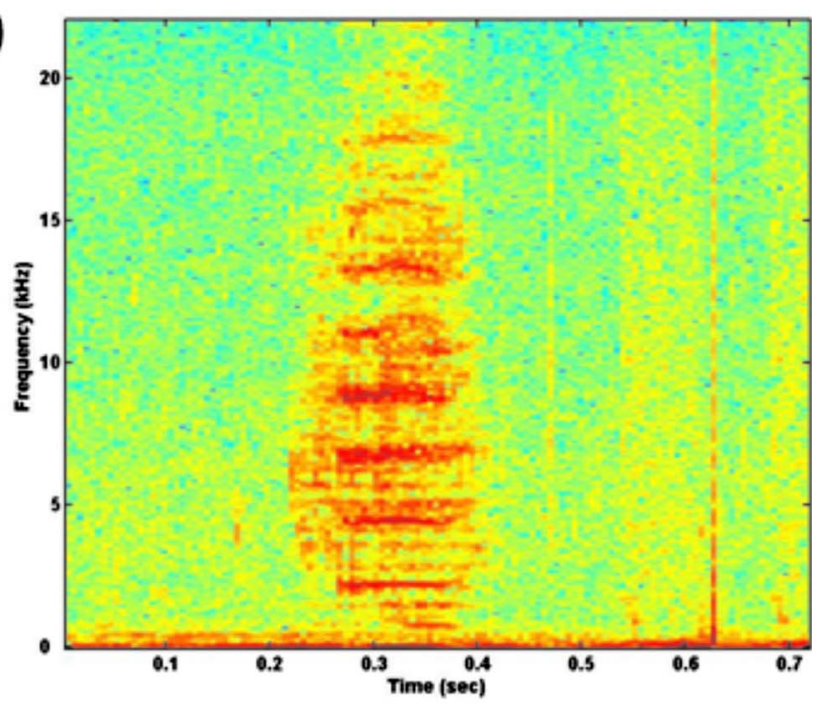

d)

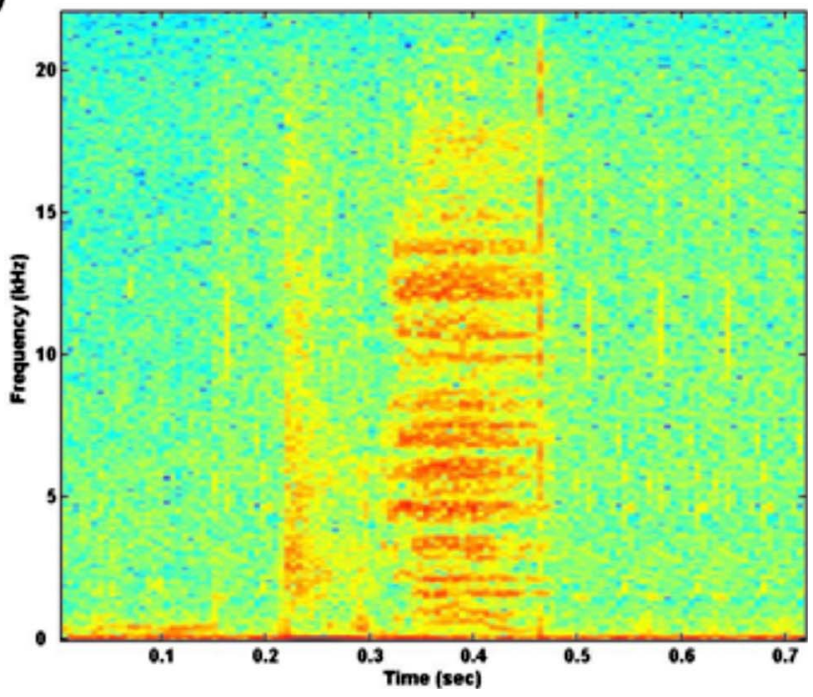

FIG. 1. (Color online) Spectrogram of manatee vocalization exemplars: (a) chirp, (b) chirp, (c) squeak, and (d) squeak. Spectrograms are plotted on a relative decibel scale. Black stars indicate inflection points.

did not measure inflection points as one of the vocalization parameters, which was the primary categorization parameter in this study.

The range of source levels obtained in this study (105$150 \mathrm{~dB}$ rms re $1 \mu \mathrm{Pa}$ at $1 \mathrm{~m}$ ) overlapped with the range of source levels previously reported $(90-138 \mathrm{~dB}$ rms re $1 \mu \mathrm{Pa}$ at $1 \mathrm{~m}$ ) (Nowacek et al., 2003; Phillips et al., 2004). Average

TABLE V. Summary table of the average parameter values for chirps and squeaks. The reported $p$-value should be compared with a Bonferroni adjusted alpha value of 0.01 for all parameters.

\begin{tabular}{|c|c|c|c|c|}
\hline & Chirps & Squeaks & $t$ stat & $p$-value \\
\hline Sample size $(n)$ & 1168 & 375 & & \\
\hline Duration (ms) & $221.8 \quad(93)$ & $198.4 \quad(69)$ & 4.47 & $<0.001$ \\
\hline Freq range $(\mathrm{Hz})$ & $15,033 \quad(3915)$ & $12,776 \quad(4614)$ & 9.28 & $<0.001$ \\
\hline Min freq $(\mathrm{Hz})$ & $1,804 \quad(704)$ & $1,358 \quad(868)$ & 9.7 & $<0.001$ \\
\hline Max freq $(\mathrm{Hz})$ & $18,026 \quad(3953)$ & $14,135 \quad(4647)$ & 11.02 & $<0.001$ \\
\hline Peak freq $(\mathrm{Hz})$ & $5,097 \quad(2721)$ & $3,341 \quad(1884)$ & 11.63 & $<0.001$ \\
\hline
\end{tabular}

source level for chirps was $122 \pm 6.5 \mathrm{~dB}$ rms re $1 \mu \mathrm{Pa}$ at 1 $\mathrm{m}$. Average squeak source level was $120 \pm 6.8 \mathrm{~dB}$ rms re $1 \mu \mathrm{Pa}$ at $1 \mathrm{~m}$. These average source levels were greater than the means of 100 and $112 \mathrm{~dB}$ re $1 \mu \mathrm{Pa}$ at $1 \mathrm{~m}$ previously reported (Nowacek et al., 2003; Phillips et al., 2004). This difference could result from the selection in this study for source level calculations of vocalizations that exceeded the 3 $\mathrm{dB}$ threshold criteria. Quieter vocalizations tended to have less sharp onset and offset, were more likely to be masked by background noise, and were therefore more likely to be eliminated from further analysis. Source levels reported here therefore reflect a sample that was biased to represent relatively high signal-to-noise levels for manatee vocalizations, which is likely also biased for high source levels.

Alternative explanations as to why this study obtained greater source levels include (1) that vocalizations emitted during the summer season in very turbid waters may be louder than those emitted in less turbid waters or during the winter season and (2) that there was a systematic error in the 


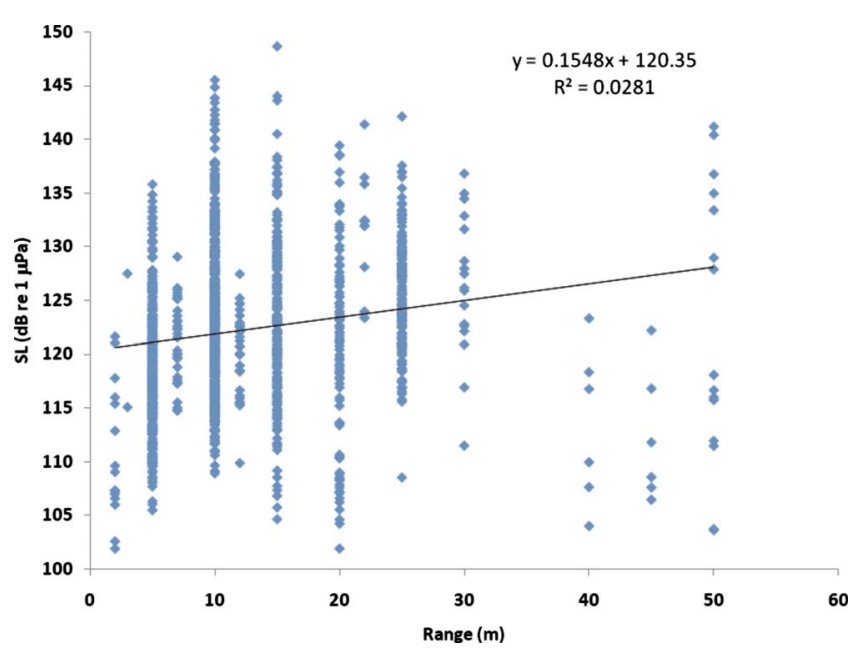

FIG. 2. (Color online) Source level plotted as a function of range for all vocalizations. The low $r^{2}$ value and $p$-value of 0.29 indicate no significant relationship.

transmission loss estimation when calculating source level. Source levels of Florida manatees reported by Nowacek et al. (2003) were obtained from a spring in Crystal River, FL, and those levels reported by Phillips et al. (2004) were obtained during the late winter/early spring season in Homosassa Springs Wildlife State Park. Environmental conditions associated with the turbid summer conditions in Sarasota may induce louder vocalizations in order to compensate for decreased visual range. Systematic error in the transmission loss estimates for calculating source level was unlikely, as there was no relationship between source level and range to the vocalizing animals $(p=0.29)$ (Fig. 2).

\section{A. Vocalization rate}

Average vocalization rates (including chirps and squeaks) ranged from 1.04 to 4.39 vocalizations/manatee/5 min period. These values correspond well to the rates of $0.25-4.75$ and 1-2 vocalization/manatee/5 min period previously reported by Bengtson and Fitzgerald (1985) and Phillips et al. (2004), respectively. A mixed model ANCOVA tested the hypothesis that all fixed effects regression slopes were equal to zero $\left(H_{0}: B_{1}=B_{2}=B_{3}=B_{n}=0\right)$. Model results showed significant interactions between behavior and both LFN and MFN, indicating that the slopes were not all equal to zero (Table VI). Pairwise comparisons indicated that rates under average noise conditions in the LFN band were lower during feeding than resting and lower during resting than socializing (Table VI). Rates solely within the social behavior state also decreased with increasing LFN level (Table VI). Patterns seen for rates in association with MFN were similar. Resting vocal rates were lower than social vocal rates under average noise levels, whereas feeding rates were lower than social rates under high MFN levels. Rates solely within the feeding behavioral state decreased with increasing MFN levels (Table VI).

\section{B. Chirp usage}

A mixed model ANCOVA was run on the chirp vocalization parameters of source level, duration, frequency range, minimum frequency, maximum frequency, and peak frequency of the dominant harmonic. Table VI shows all the significant fixed effects and pairwise comparisons of significant interactions. In summary, manatees did not show modification of chirp source level, frequency range, minimum frequency, or maximum frequency in relation to behavioral context, group composition, or noise level. Chirp call durations were altered based on calf presence and noise level. Chirps had longer durations when calves were present under conditions of low and average LFN levels. Chirps were also longer when calves were present under conditions of average and high MFN levels. The peak frequency of the dominant harmonic of chirp vocalizations was context dependent. There was a significant interaction between group size and behavior. Multiple comparisons revealed that the peak frequency of chirps for manatees resting in groups equal to or greater than five animals was higher than equivalent groups of socializing manatees. A significant interaction between calf presence and MFN was also observed in relation to peak frequency. Under low MFN levels, chirps had lower peak frequencies when calves were present compared to when they were absent. Interestingly, when calves were absent, peak frequencies decreased with increasing MFN levels.

\section{Squeak usage}

A mixed model ANCOVA was used to investigate the effect of noise on squeak vocalization parameters. Table VI shows all the significant fixed effects and pairwise comparisons of significant interactions. In summary, modification of squeaks was not observed in relation to noise level, group composition, or behavioral context for any frequency parameter. Squeak source levels were modified as a function of HFN and behavioral state. Under conditions of low HFN levels, squeaks emitted during feeding were louder than during milling. The opposite was true under high levels of HFN. In high levels of HFN, squeaks emitted during milling were louder than during feeding. Durations of squeaks were shorter under high levels of LFN when calves were present. This was opposite of the trend observed for chirp durations. Lastly, squeak durations increased with increased in LFN when no calves were present.

\section{DISCUSSION}

Whether most marine mammals can adjust the frequencies, duration, rate, and source levels of their various call types to increase communication range in the presence of noise has not been extensively studied (Richardson et al., 1995). This study investigated whether manatees modify vocal parameters to compensate for environmental noise. It was discovered that manatees exhibited a number of vocal compensation techniques and that the vocal parameters modified were context dependent. Compensation techniques observed in response to LFN levels included a decrease in vocalization rate which was dependent on behavioral state, an increase in chirp durations when calves were present, and increased squeak durations as noise level increased when calves were absent. Similarly, behavior-dependent decreases in vocalization rate and increases in chirp durations with calf presence 
TABLE VI. Significant ANCOVA effects and pairwise comparisons. The $\times$ denotes type 3 test for fixed effects. Across categorical state comparisons were made with least squares means with a Tukey-Kramer adjustment. Covariate relationships within categorical states were tested with linear regression. In the Significant Relationships descriptions, the values in parentheses are mean values of the measured parameter.

\begin{tabular}{|c|c|c|c|c|c|}
\hline Category & Response & Significant Effects & $\begin{array}{l}\text { Effect } F \text { value } \\
(p \text { value })^{*}\end{array}$ & Significant relationships & Relationship statistics \\
\hline & $\begin{array}{l}\text { Rate } \\
\text { (calls/indv/5 min) }\end{array}$ & LFN $\times$ behavior & $\begin{array}{l}F_{3,27}=3.17 \\
(0.040)\end{array}$ & $\begin{array}{l}\text { Feeding }(1.08)<\text { resting }(2.12) \\
\text { for average noise levels (across) }\end{array}$ & $t=3.13 ; p=0.02 ; \mathrm{df}=27$ \\
\hline & & & & $\begin{array}{l}\text { Resting }(2.12)<\text { social }(2.61) \text { for } \\
\text { average noise levels (across) }\end{array}$ & $t=-3.83 ; p=0.004 ; \mathrm{df}=27$ \\
\hline & & & & $\begin{array}{l}\text { Social rates decreased with } \\
\text { increasing noise (within) }\end{array}$ & $\begin{array}{l}y=-0.16 x+12.6 ; r^{2}=0.25 \\
F_{1,14}=4.8 ; p=0.04\end{array}$ \\
\hline & & MFN $\times$ behavior & $\begin{array}{l}F_{3,27}=3.71 \\
(0.023)\end{array}$ & $\begin{array}{l}\text { Resting }(2.06)<\text { social }(2.52) \text { for } \\
\text { average noise levels (across) }\end{array}$ & $t=-3.23 ; p=0.02 ; \mathrm{df}=27$ \\
\hline & & & & $\begin{array}{l}\text { Feeding }(1.63)<\text { social }(3.31) \text { for } \\
\text { high noise condition (across) }\end{array}$ & $t=-3.40 ; p=0.01 ; \mathrm{df}=27$ \\
\hline & & & & $\begin{array}{l}\text { Feeding rates decreased with } \\
\text { increasing noise (within) }\end{array}$ & $\begin{array}{l}y=-0.10 x+8.2 ; r^{2}=0.20 \\
F_{1,22}=5.4 ; p=0.03\end{array}$ \\
\hline \multirow[t]{11}{*}{ Chirp } & $\mathrm{SL}(\mathrm{dB})$ & None & & & \\
\hline & Duration (ms) & $\begin{array}{l}\mathrm{LFN} \times \text { calf } \\
\text { presence }\end{array}$ & $\begin{array}{l}F_{1,39}=7.35 \\
(0.010)\end{array}$ & $\begin{array}{l}\text { Present }(219.8)>\text { absent }(194.4) \\
\text { for low noise levels (across) }\end{array}$ & $t=-3.38 ; p=0.002 ; \mathrm{df}=39$ \\
\hline & & & & $\begin{array}{l}\text { Present }(231.5)>\text { absent }(201.8) \\
\text { for average noise levels (across) }\end{array}$ & $t=-2.20 ; p=0.03 ; \mathrm{df}=39$ \\
\hline & & $\begin{array}{l}\text { MFN } \times \text { calf } \\
\text { presence }\end{array}$ & $\begin{array}{l}F_{1,39}=8.77 \\
(0.005)\end{array}$ & $\begin{array}{l}\text { Present }(224.1)>\text { absent }(201.5) \\
\text { for average noise levels (across) }\end{array}$ & $t=-2.66 ; p=0.01 ; \mathrm{df}=39$ \\
\hline & & & & $\begin{array}{l}\text { Present }(266.2)>\text { absent }(191.8) \\
\text { for high noise levels (across) }\end{array}$ & $t=-3.50 ; p=0.001 ; \mathrm{df}=39$ \\
\hline & Freq range $(\mathrm{Hz})$ & None & & & \\
\hline & Min freq $(\mathrm{Hz})$ & None & & & \\
\hline & Max freq $(\mathrm{Hz})$ & None & & & \\
\hline & Peak freq $(\mathrm{Hz})$ & $\begin{array}{l}\text { Group size } \times \\
\text { behavior }\end{array}$ & $\begin{array}{l}F_{3,32}=4.93 \\
(0.006)\end{array}$ & $\begin{array}{l}\text { For groups } \geq 5, \text { resting }(6785) \\
>\operatorname{social}(5071)\end{array}$ & $\begin{array}{l}t=2.87-3.53 \\
p=0.007-0.04 ; \mathrm{df}=32\end{array}$ \\
\hline & & $\begin{array}{l}\text { MFN } \times \text { calf } \\
\text { presence }\end{array}$ & $\begin{array}{l}F_{1,32}=7.34 \\
(0.011)\end{array}$ & $\begin{array}{l}\text { Present }(4702)<\text { absent }(5250) \\
\text { for low noise levels (across) }\end{array}$ & $t=3.27 ; p=0.003 ; \mathrm{df}=32$ \\
\hline & & & & $\begin{array}{l}\text { Absent: peak frequency decreased } \\
\text { with increasing noise levels } \\
\text { (within) }\end{array}$ & $\begin{array}{l}y=-70.4 x+8691 ; r^{2}=0.15 \\
F_{1,32}=5.5 ; p=0.03\end{array}$ \\
\hline \multirow[t]{8}{*}{ Squeak } & $\mathrm{SL}(\mathrm{dB})$ & $\mathrm{HFN} \times$ behavior & $\begin{array}{l}F_{3,21}=3.60 \\
(0.032)\end{array}$ & $\begin{array}{l}\text { Feeding }(123.6)>\text { milling }(119.0) \\
\text { for low noise levels (across) }\end{array}$ & $t=2.95 ; p=0.04 ; \mathrm{df}=21$ \\
\hline & & & & $\begin{array}{l}\text { Feeding }(120.8)<\text { milling }(130.3) \\
\text { for high noise levels (across) }\end{array}$ & $t=-2.94 ; p=0.04 ; \mathrm{df}=21$ \\
\hline & Duration (ms) & $\begin{array}{l}\mathrm{LFN} \times \text { calf } \\
\text { presence }\end{array}$ & $\begin{array}{l}F_{3,19}=5.33 \\
(0.030)\end{array}$ & $\begin{array}{l}\text { Present }(156.6)<\text { absent }(236.2) \\
\text { for high noise levels (across) }\end{array}$ & $t=2.45 ; p=0.02 ; \mathrm{df}=19$ \\
\hline & & & & $\begin{array}{l}\text { No calves: durations increased in } \\
\text { high noise levels (within) }\end{array}$ & $\begin{array}{l}y=4.9 x-76.7 ; r^{2}=0.22 \\
F_{1,23}=6.6 ; p=0.02\end{array}$ \\
\hline & Freq range $(\mathrm{Hz})$ & None & & & \\
\hline & Min freq $(\mathrm{Hz})$ & None & & & \\
\hline & Max freq $(\mathrm{Hz})$ & None & & & \\
\hline & Peak freq $(\mathrm{Hz})$ & None & & & \\
\hline
\end{tabular}

were observed in response to MFN. Peak frequency of chirp vocalizations decreased with increasing MFN, and peak frequencies were higher when calves were absent and MFN was low. Vocal responses to HFN included a source level pattern shift.

Further discussion places the observed patterns of manatee vocal compensation in a broader framework of costs and benefits relating to effective communication under conditions of different group composition and behavioral contexts. Vocalization effort is the term used here to represent the physical cost of acoustic communication. Vocalization effort refers to the energy expenditure of producing a call and is a func- tion of source level, vocalization rate, signal duration, and/or vocalization frequency. Vocalization effort is increased by increasing call amplitude, rate, and duration. Shifting to higher frequencies may take more energy for a manatee to produce, thus increasing vocalization effort, if the sound production mechanism of the signaler is tuned to the frequencies usually used. It has been argued that high frequency sounds are more costly to produce because it takes more energy to produce sounds that are closer in wavelength to the size of the sound-producing and resonating structures (Ryan, 1986).

Increasing vocalization effort is one mechanism to increase or maintain effective communication in the presence 
of environmental noise. Manatees exhibited marked changes in vocalization effort by selectively decreasing vocalization rate, increasing duration, decreasing peak frequencies, and altering source levels in response to noise levels. The specific vocal parameter altered was a function of behavioral state, calf presence, noise level, and frequency of noise. Manatees emitted longer chirps when calves were present, whereas the effect on squeaks was the opposite. The difference in the results between chirps and squeaks hints at a mother-calf proximity maintenance function of chirps, as suggested by Sousa-Lima et al. $(2002,2008)$. Increased vocal effort in this circumstance may aid in more effective communication geared toward maintaining mother-calf contact. Alternatively, vocal effort decreased with increasing noise levels due to a decrease in vocalization rate during social and feeding behaviors. This pattern may indicate that manatees wait until it is quiet to vocalize while socializing and feeding, exhibiting only minimal vocalization effort during periods of high noise. Such a pattern of increased signaling during periods of low noise has been documented to avoid interference from conspecific vocalizations (e.g., Cody and Brown, 1969; Ficken et al., 1974) or anthropogenic noise (Sun and Narins, 2005; Parks et al., 2007; Sousa-Lima and Clark, 2008). Another way manatees increased their vocal effort was by increasing source level. Under low noise levels the source level of squeaks emitted during feeding was less than that emitted during milling. However, under high noise levels, the source level of squeaks recorded during milling was higher than when feeding. Manatees engaged in milling behaviors tend to separate more than when feeding, resting, or socializing, so it is possible that manatees need to increase vocalization effort under conditions of elevated noise levels to compensate for noise effects given the greater ranges between signaler and receiver at these times.

According to communication theory, manatees should only increase their vocalization effort when the benefits of effective vocal communication outweigh the cost of increased energy expenditure. Some benefits of effective communication include maintaining mother-calf contact, maintaining group cohesion, and signaling intentions. One important factor driving vocalization effort is the range over which the signaler and receiver must effectively communicate. Typical ranges between animals will vary as a function of context, and vocalization effort would be expected to vary accordingly. Consequently, a common reason for increasing the energy involved in vocalizing would be to maintain the required range of effective communication in increased noise. Increased vocal effort resulting from increases in source level in elevated noise conditions is a well known response known as the Lombard effect in humans, and has been demonstrated for other animals including nightingales (Luscinia megarhynchos), beluga whales (Delphinapterus leucas), common marmoset (Callithrix jacchus), and cats (Brumm, 2004; Egnor et al., 2006; Nonaka et al., 1997; Scheifele et al., 2005). Results presented here indicate that manatees can now be included in this list.

Our findings demonstrate that manatees do alter their vocalization effort, as indicated by changes in usage and structure, as a function of behavior and group composition.
However, there was no simple or clear pattern that emerged from the results. Clear-cut results are often rare in biology and variation can be indicative of animals using different strategies to compensate for the same stressor (i.e., one animal increases source level while another increases duration to compensate for noise). More extensive studies are needed to provide details of how these changes affect the probability of detecting and classifying the signals, how net change in vocalization effort relates to energetic expenditure, and whether or not the mode of compensation is indicative of call function. The findings presented here pertain only to the Florida manatee during the nonwinter months and in very turbid environments. Whether the observed patterns can be generalized to all seasons and habitats also requires additional studies.

\section{ACKNOWLEDGMENTS}

Special thanks are extended to the staff in the Manatee Research Program at Mote Marine Laboratory for their support of this study. This research would not have been possible without the aid of numerous Mote interns, and the sharing of knowledge and time from the staff. We also wish to thank anonymous reviewers for their insightful comments on a previous version of this manuscript. This project was conducted under permits issued by the U.S. Federal Fish and Wildlife Service to David Mann at the University of South Florida (MA051709-0) and the Fish and Wildlife Research Institute (MA773494-7), and it compiled with all the current federal and state laws. This research was supported by a P.E.O. Scholar Award and National Defense Science and Engineering Fellowship awarded to Jennifer Miksis.

Bengston, J. L. (1981). "Ecology of manatees (Trichechus manatus) in the St. Johns River, Florida," Ph.D. dissertation, University of Minnesota, Minneapolis, MN.

Bengtson, J. L., and Fitzgerald, S. M. (1985). "Potential role of vocalizations in West Indian manatees," J. Mammal. 66, 816-819.

Brumm, H. (2004). "The impact of environmental noise on song amplitude in a territorial bird," J. Anim. Ecol. 73, 434-440.

Brumm, H., and Slabbekoorn, H. (2005). "Acoustic communication in noise," Adv. Stud Behav. 35, 151-209.

Brumm, H., and Slater, P. J. B. (2006). "Ambient noise, motor fatigue, and serial redundancy in chaffinch song," Behav. Ecol. Sociobiol. 60, 475481.

Cody, M. L., and Brown, J. H. (1969). "Song asynchrony in neighbouring bird species," Nature (London) 222, 778-780.

Egnor, S. E. R., Iguina, C. G., and Hauser, M. D. (2006). "Perturbation of auditory feedback causes systematic perturbation in vocal structure in adult cotton-top tamarins," J. Exp. Biol. 209, 3652-3663.

Ficken, R. W., Ficken, M. S., and Hailman, J. P. (1974). "Temporal pattern shifts to avoid acoustic interference in singing birds," Science 183, 762763.

Foote, A. D., Osborne, R. W., and Hoelzel, A. R. (2004). "Whale-call response to masking boat noise," Nature (London) 428, 910.

Gerstein, E. R., Gerstein, L., Forsythe, S. E., and Blue, J. E. (1999). "The underwater audiogram of the West Indian manatee (Trichechus manatus)," J. Acoust. Soc. Am. 105, 3575-3583.

Hartman, D. S. (1979). "Ecology and behavior of the manatee," Trichechus manatus, in Florida (American Society of Mammalogy, Special Publication 5.

Ketten, D. R., Odell, D. K., and Domning, D. P., 1992, "Structure, function, and adaptation of the manatee ear," in Marine Mammal Sensory Systems, edited by J. A. Thomas, R. A. Kastelein, and A. Ya. Supin (Plenum, New York), pp. 77-95.

Lengagne, T., Aubin, T., Lauga, J., and Jouventin, P. (1999). "How do king 
penguins (Aptenodytes patagonicus) apply the mathematical theory of information to communicate in windy conditions?," Proc. R. Soc. London, Ser. B 266, 1623-1628

Lesage, V. C., Barrette, C., and Kingsley, M. C. S. (1999). "The effect of noise from an outboard motor and ferry on the vocal activity of beluga (Delphinapterus leucas) in the St. Lawrence Estuary, Canada," Abstracts of the Tenth Biennial Conference on the Biology of Marine Mammals, Galveston, TX

Littell, R. C., Milliken, G. A., Stroup, W. W., Wolfinger, R. D., and Schabenberger, O. (2006), SAS for Mixed Models, 2nd ed. (SAS, Cary, NC).

Miksis-Olds, J. L., Donaghay, P. L., Miller, J. H., Tyack, P. L., and Nystuen, J. A. (2007). "Noise level correlates with manatee use of foraging habitats," J. Acoust. Soc. Am. 121, 3011-3020.

Miksis-Olds, J. L., and Miller, J. H. (2006). "Transmission loss in manatee habitats," J. Acoust. Soc. Am. 120, 2320-2327.

Miller, P. J. O., Biassoni, N., Samuels, A., and Tyack, P. L. (2000). "Whale songs lengthen in response to sonar," Nature (London) 405, 903.

Nonaka, S., Takahashi, R., Enomoto, K., Katada, A., and Unno, T. (1997) "Lombard reflex during PAG-induced vocalizations in decerebrate cats," Neurosci. Res. 29, 283-289.

Nowacek, D. P., Casper, B. M., Wells, R. S., Nowacek, S. M., and Mann, D. A. (2003). "Intraspecific and geographic variation of West Indian manatee (Trichechus manatus spp.) vocalizations (L)," J. Acoust. Soc. Am. 114, 66-69.

Oppenheim, A. V., Schafer, R. W., and Buck, J. R. (1999). Discrete-Time Signal Processing, 2nd ed. (Prentice-Hall, Englewood Cliffs, NJ).

O'Shea, T. J., and Hartley, W. C. (1995). "Reproduction and early-age survival of manatees at Blue Spring, upper St. Johns River, Florida," in Population Biology of the Florida Manatee, edited by T. J. O'Shea, B. B. Ackerman, and H. F. Percival (National Biological Service Information and Technology, Gainesville, FL), pp. 157-170.

Parks, S., Clark, C., and Tyack, P. L. (2007). "Short and long-term changes in right whale calling behavior: The potential effects of noise on acoustic communication," J. Acoust. Soc. Am. 122, 3725-3731.

Parks, S. E. (2003). "Acoustic communication in the North Atlantic right whale, Eubalaena glacialis," Ph.D. dissertation, MIT, Woods Hole, MA. Penna, M., Pottstock, H., and Velasquez, N. (2005). "Effect of natural and synthetic noise on evoked vocal responses in a frog of the temperate austral forest," Anim. Behav. 70, 639-651.

Phillips, R., Niezrecki, C., and Beusse, D. O. (2004). "Determination of West Indian manatee vocalization levels and rate," J. Acoust. Soc. Am. 115, 422-428.

Richardson, W., Greene, C., Malme, C., and Thomson, D. (1995). Marine Mammals and Noise (Academic, San Diego, CA).

Ryan, M. J. (1986). "Factors influencing the evolution of acoustic communication: Biological constraints," Brain Behav. Evol. 28, 70-82.

Scheifele, P. M., Andrew, S., Cooper, R. A., Darre, M., Musiek, F. E., and Max, L. (2005). "Indication of a Lombard vocal response in the St. Lawrence River beluga," J. Acoust. Soc. Am. 117, 1486-1492.

Schevill, W. E., and Watkins, W. A. (1965). "Underwater calls of Trichechus (Manatee)," Nature (London) 205, 373-374.

Slabbekoorn, H., and Peet, M. (2003). "Birds sing at a higher pitch in urban noise," Nature (London) 424, 267.

Smith, K. B. (2001). "Convergence, stability, and variability of shallow water acoustic predictions using a split-step Fourier parabolic equation model," J. Comput. Acoust. 9, 243-285.

Sousa-Lima, R. S., and Clark, C. W. (2008). "Modeling the effect of boat traffic on singing activity of humpback whales (Megaptera novaeangliae) in the Abrolhos National Marine Park, Brazil," Can. Acoust. 36, 174-181.

Sousa-Lima, R. S., Paglia, A. P., and da Fonseca, G. A. B. (2002). "Signature information and individual recognition in the isolation calls of the Amazonian manatees, Trichechus inunguis (Mammalia: Sirenia)," Anim. Behav. 63, 301-310

Sousa-Lima, R. S., Paglia, A. P., and da Fonseca, G. A. B. (2008). "Gender, age, and identity in the isolation calls of Antillean manatees (Trichechus manatus manatus)," Aquat. Mamm. 34, 109-122.

Sun, J. W. C., and Narins, P. M. (2005). "Anthropogenic sounds differentially affect amphibian call rate," Biol. Conserv. 121, 419-427.

Urick, R. J. (1983). Principles of Underwater Sound, 3rd ed. (Peninsula, Los Altos, CA). 